\title{
PORTRAYING THE CONTRIBUTION OF INDIVIDUAL BEHAVIORS TO TEAM COHESION AND PERFORMANCE
}

\author{
Bonny Parke, Ph.D. \\ San Jose State University \\ Judith Orasanu, Ph.D. \\ NASA Ames Research Center
}

\begin{abstract}
Behaviors of individuals in teams both contribute to and are molded by team dynamics. How they do so has been the subject of much research. A method of portraying individuals' behaviors in teams, the Team Diagramming Method (TDM) is presented. Behaviors are rated by other team members on three important dimensions: positivity/negativity, dominant/submissive, and task-orientedness/expressiveness. A study of 5-person teams engaging in a 3-day moon simulation task demonstrated that measures of these perceived behaviors as well as the variances of these behaviors correlated with cohesion measures and performance. The method shows strengths and weaknesses of particular teams and, by comparison with high-performing teams, suggests interventions based on individual as well as team behaviors.
\end{abstract}

\section{BACKGROUND}

Team and group cohesion has been associated with higher performance (Carron, Coman, Wheeler, \& Stevens, 2002; Mullen \& Copper, 1994; Oliver, Harman, Hoover, Hayes, \& Pandhi, 2000), as well as resilience to stress and trauma (Eid \& Johnsen, 2002; Phipps \& Mulhern, 1995). Cohesion is typically measured by members rating the degree of attraction they feel to the team using instruments such as the Group Environment Scale (GES) (Moos \& Humphrey, 1974) or the Group Environment Questionnaire (GEQ) (Carron, Widmeyer, \& Brawley, 1985). However, with this approach, the contribution of individual team member behaviors to team cohesion are obscured. A different approach, the Team Diagramming Method (TDM), involves rating individual team members' behaviors on three important dimensions of group interaction. The results enable one to see the contribution of individual behaviors to cohesion as well as to other important aspects of team functioning. The ratings are made on a 26item behavioral adjective list by the team members themselves, by an external observer, or through use of an actby-act scoring method. Based on the ratings of all team behaviors, team level variables can be generated.

The primary goal of this study was to determine the extent to which these team level variables, derived from all team members' rated behaviors, were associated with previous methods of measuring cohesion and with performance. A secondary goal was to determine the stability of TDM measures over time by comparing team level variables based on ratings early and later in the team's work together.

\section{DESCRIPTION OF TDM AND RELATED RESEARCH}

The TDM is derived from the work of Bales \& Cohen (1979). It builds on the finding that some of the most important dimensions of team or group interaction are positive/negative behaviors, dominant/submissive behaviors, and task-oriented/expressive behaviors (see Couch, 1960; Emmerich, 1968, 1973; Isenberg \& Ennis, 1981; Parke \& Houben, 1985; Schaefer, 1971; Schaefer, Droppleman, \&

Kalverboaer, 1965; Wish, D'Andrade, \& Goodnow, 1980). Bales (1953) has documented the task-oriented and expressive cycles of well-functioning groups, and behaviors on this dimension reflect its polarity in group or team settings.

\section{Previous Research}

Classroom Groups. An example from previous research on classroom groups illustrates how data from the TDM are depicted (Parke \& Houben, 1985). Classrooms were divided into seven types, based on statistical properties of 96 teacherrated classroom groups. Positive/negative behavior is represented on the $\mathrm{x}$-axis and task-oriented/expressive behavior is on the y-axis. Dominant/submissive behavior is represented by varying sizes of circles, with larger circles representing more dominant behavior. These circle sizes are used as weights in the statistical analysis of team properties since the more dominant the behavior, the more it impacts the team or group. In the examples below, red circles indicate behavior of females and blue circles indicate behavior of males. Figure 1 shows a Unified classroom group with most members' behaviors close together in the positive, taskoriented quadrant. Figure 2 shows a Polarized classroom group, with a large proportion of the group rebelling in the negative/expressive quadrant.

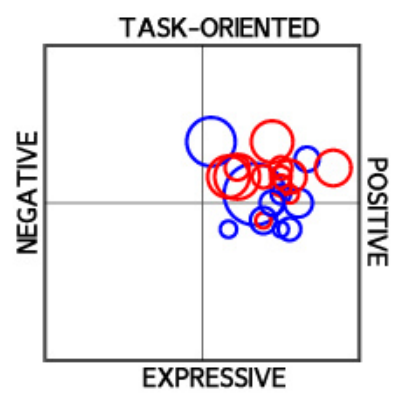

Figure 1.Unified $5^{\text {th }}$ grade group (Parke \& Houben, 1985)

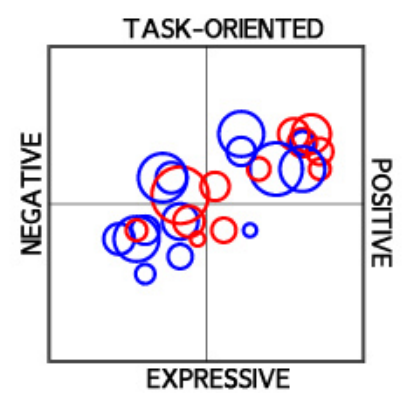

Figure 2. Polarized $3-4^{\text {th }}$ grade group (Parke \& Houben, 1985) 
Figures 3 and 4 show two types of expressive behavior. In Figure 3, the males are joking around in a positive fashion that denies the importance of tasks; in Figure 4, they are actively and negatively rebelling against tasks.

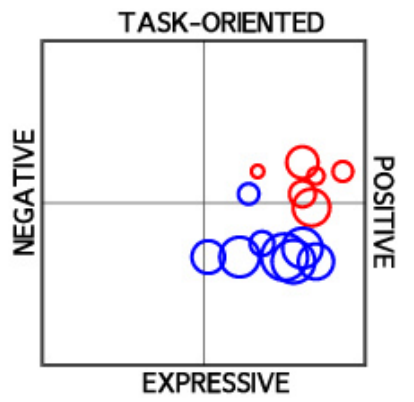

Figure 3. Parallel Fragmented Group Middle School

(Parke \& Houben, 1985)

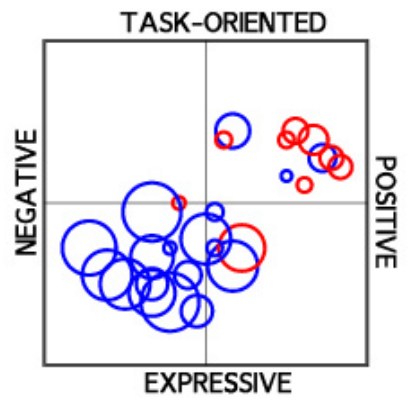

Figure 4. Polarized Group Middle School (Parke \& Houben, 1985)

Simulated 3-person Cockpit Crews. Figures 5 and 6 show the lowest and highest error crews in a simulator study involving twelve 3-person commercial airline pilots, with Captain, First Officer, and Second Officer behaviors depicted (Parke, et al., 2000). Three observers rated the video-taped behaviors both with a 26-item adjective rating list (described later) and with act-by-act scoring (each act is coded on an applicable dimension or combination of dimensions). Crew errors were determined by subject matter experts. Making fewer errors was related to low average distance between behaviors on the diagram plane $(r=.40, p=.05)$ and to the crew's center of gravity being positive $(\mathrm{r}=.54, \mathrm{p}<.01)$ and expressive $(r=.38, p=.07)$. The crew with the fewest errors in Figure 5 can be statistically defined as a Unified Team; the crew with the most errors in Figure 6 as a Polarized Team (see Parke \& Houben, 1985). The team diagram in Figure 6 highlights the contribution of the Captain's behavior to the polarization, i.e., his negativity.

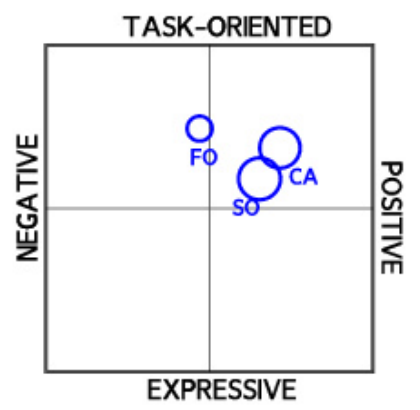

Figure 5. Crew with fewest errors (Parke, et al., 2000)

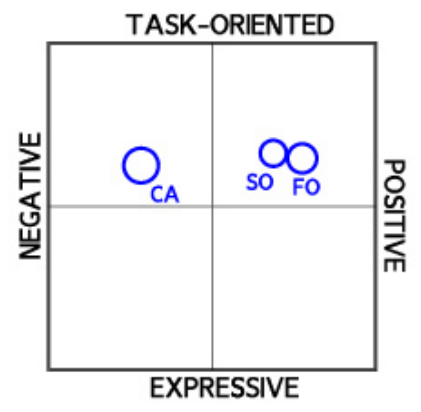

Figure 6. Crew with most errors (Parke, et al., 2000) less stress in the group, as rated by group members and observers. Fine also demonstrated a modeling and contagion effect. He introduced a dominant confederate in the second hour of group meetings and showed that others moved towards the confederate in the diagram plane, i.e., became more similar to the confederate (as ascertained by self and other ratings, and coding of behaviors by observers). Hence the diagram plane is a dynamic space with clustering of behaviors (Parke \& Houben, 1988). However, the opposite occurred on the dominance dimension: the other team members contributed less after inclusion of the dominant confederate.

Additional researchers who have found that closeness on the diagram plane, i.e., similarity in positive and task-oriented behaviors, indicates a more cohesive group are Keyton \& Springston (1990) and Jaffee \& Nebebzahl (1990), although Keyton and Springston note that this is likely to be the case only when there are some behaviors on the positive side of the space. To the authors' knowledge, the groups and teams studied thus far have all had some behaviors in the positive side of the space. However, additional restrictions on the definition of a Unified team will need to be added to cover teams with no positive behaviors.

\section{Hypotheses}

Given the results of the previous research, it was predicted that several TDM variables would be associated with greater cohesion and/or performance: closer proximity on the diagram plane (i.e. average distance weighted by dominance, a more positive center of gravity (i.e. average rating on the positive/negative dimension weighted by dominance), a more expressive center of gravity, a lower index of polarization on the diagram plane, a higher average dominance level, and a lower level of dominance polarization (i.e. more equal participation).

In addition, it was predicted that TDM would be helpful in portraying the contribution of individuals' behaviors to team cohesion and performance.

\section{METHOD}

\section{Participants}

Flyers and online bulletin boards were used to recruit 120 US citizens (48 female) for the study. Participants were between 19 and 56 years old $(M=33.53, S D=10.45)$. All participants had completed at least two years of college, with 52 completing four years of college and 15 with advanced degrees. (A more complete description of this study can be found in Orasanu, Fischer, Parke, McDonnell, Kraft \& Anderson, 2009; see also Fischer, McDonnell, \& Orasanu, 2007.)
Other studies. Proximity on the diagram plane has been shown by Fine (1986) to be related to greater enjoyment and 


\section{Study Task}

The task used in the study was the Distributed Dynamic Decision-Making (DDD) simulation task environment developed by Aptima, Inc. (Entin et al., 1998). There were two types of simulated DDD scenarios-search and rescue missions in Antarctica or a search for water resources on the lunar surface. Study participants worked in teams of five on linked computer terminals. Communication between team members was supported by email and a voice system. Team members' main objectives during a mission were either to locate and rescue a lost crew and to complete the missing crew's repair mission, or to retrieve an important downed satellite. In order to succeed in these tasks, team members had to develop a search strategy (e.g., divide the emergency tasks), assign and coordinate tasks (e.g., determine who keeps track of team progress), manage resources (e.g., be mindful of supply requirements), and share task-critical information.

During mission training, members of a team were randomly assigned the role of search team member or base station coordinator, which they maintained throughout the study. The base station coordinator assisted the search team with refueling and re-supplying their rovers. Satellite messages concerning environmental hazards, weather systems and objects possibly relevant to locating the downed satellite and missing team were transmitted only to the base station. The base coordinator had to decide which information to disseminate and whether to address the entire team or individual members. No team member was designated as the official leader, nor were team coordination and communication constrained or defined by the experimenters.

All missions were sufficiently difficult that they could not be completed unless team members worked together to plan, manage workload and resources, coordinate, and communicate critical information.

\section{Study Design}

Participants were randomly assigned to a five-person gender-mixed team (3 males, 2 females) to compose 24 groups. The experiment extended over four days. On Day 1 participants were trained to use the experimental software and completed a practice scenario. On the following three days teams worked through six experimental scenarios, one moderate and one difficult scenario per day. Scenario order was counterbalanced across and within days. Prior to each scenario, participants had 20 minutes to plan for the upcoming mission. Both individual and team performance measures were recorded and time-stamped by the DDD software.

\section{Measures}

Team Diagramming Method (TDM). Team members rated each member of their team twice using a 26-item behavioral checklist to indicate the frequency of team member behaviors (e.g., active, gets angry, is appreciative). Ratings were made on a sliding scale within a 3-point Likert scale:
Seldom, Sometimes, and Often. Item-to-scale and inter-rater reliabilities of this instrument are high (Bales \& Cohen, 1979; Parke, 1985; Rywick, 1987). The behavioral ratings were made at the end of their first day of testing (after completing the second lunar search mission) and at the end of the study.

The Group Environment Scale (GES). The GES (Moos \& Humphrey, 1974) is a self-report measure of perceived social climate. The 4-minute version consists of 48 items comprising 6 subscales: cohesion (tightness of the group), expressivity (tendency to share thoughts and express emotions in a group), independence (members can depend on themselves), innovation (members are encouraged to be creative), anger and aggression (expressed hostility in a group), and order and organization (group is organized versus disorganized). The GES was administered once, at the end of the study.

Sociometric ratings of task and social cohesion. This measure was based on the sociogram approach (Moreno, 1960), but instead of asking team members to rank order members of their team, they were asked once, at the end of the study, to rate team members on a 7-point Likert scale on how much they would like to go with each of them on a 6-month space mission (Task Cohesion) or a 2-week vacation (Social Cohesion).

Performance. The DDD task provided team performance measures (e.g., number of games completed, average scores).

\section{RESULTS}

Team Diagram Measures. Statistics that define the TDM team-level variables and seven group types are presented in detail elsewhere (Parke \& Houben, 1985) and will be only generally described here. Nearly all of the teams (20/24) were Unified and the group centers of gravity (average position on the diagram plane weighted by dominance scores) were very positive. The average distance (weighted by dominance scores) was a very low 2.9 , well under 4.9 , which is the criterion for defining a Unified Group. The average group center of gravity in the positive direction was a high +10.1 (out of +18 ; the axis endpoints in the diagram are \pm 18 units from the origin), and the average group center of gravity in the task-oriented direction was +2.0 (out of a possible +18 ).

Changes in all Teams Over Time. All centers of gravity in the groups became more positive and more expressive between the two rating times $\mathrm{p}<.01$ (sphericity not assumed), and the average dominance rating increased $(\mathrm{p}<.01)$, indicating an improvement in team functioning over time.

Consistency of TDM variables. Ratings from two days apart showed stability, especially the dominance average and dominance polarization of the group, as shown in Table 1 . 
Table 1. Consistency of TDM Variables Over Time

\begin{tabular}{|l|l|}
\hline \multicolumn{1}{|c|}{ Team Diagram Variables } & Correlations Between Times \\
\hline Average distance & $.64^{* *}$ \\
\hline Positive center of gravity & $.84^{* *}$ \\
\hline Task center of gravity & $.78^{* *}$ \\
\hline Index of polarization*** & .15 \\
\hline Dominance average & $.88^{* *}$ \\
\hline Dominance polarization & $.92^{* *}$ \\
\hline
\end{tabular}

Note: $*=$ p. $<.05, * *=\mathrm{p}<.01$.

$* * *$ The index of polarization measures the extent to which behaviors are in a line on the diagram plane (comparing the variance along the group's major axis - the weighted least square line fit through the group - to the variance along the minor axis, which is perpendicular to the major axis). With a tight clustering of behaviors (low average distance) in a team, the index of polarization would not be expected to be related to important dynamics.

DM and Group Environment Scale (GES). High cohesion as measured by the GES was associated most strongly with high average dominance activity on the TDM, $r(22)=.67$, $\mathrm{p}<.001$, as predicted. Also as predicted, GES cohesion was associated with an expressive center of gravity, $r(22)=.58$, $\mathrm{p}<.01$. Many of the other GES measures were also related to TDM variables, e.g., a high GES anger and aggression score was associated with a high average distance, $r(22)=.74, \mathrm{p}$ $<.001$, and with a negative center of gravity, $r(22)=63$, $\mathrm{p}$ $<.001$.

TDM and ratings of task and social cohesion. Table 2 shows the correlations between TDM and the ratings of task and social cohesion.

Table 2. Correlations between TDM and Task and Social Cohesion Ratings

\begin{tabular}{|l|c|c|c|c|}
\hline & \multicolumn{2}{|c|}{ Task Cohesion } & \multicolumn{2}{c|}{ Social Cohesion } \\
\hline \multicolumn{1}{|c|}{ TDM Variables } & Mean & SD & Mean & SD \\
\hline Average distance & $-.71^{* *}$ & $.66^{* *}$ & $-.57^{* *}$ & $.58^{* *}$ \\
\hline Positive center of gravity & $.81^{* *}$ & $-.62^{* *}$ & $.67^{* *}$ & $-.52^{* *}$ \\
\hline Task center of gravity & & $.41^{*}$ & $-.43^{*}$ & \\
\hline Index of polarization & & & & \\
\hline High average dominance & & & $.51^{* *}$ & $-.42^{*}$ \\
\hline Dominance polarization & & & & \\
\hline
\end{tabular}

It can be seen that there are high correlations between the team means on most of the TDM variables and the task and social cohesion measures and that they are in the expected directions.

TDM and performance. A more expressive center of gravity was associated with higher team performance (number of games completed $r(22)=.49, \mathrm{p}<.05$, and average scores, $r(22)=.48, \mathrm{p}<.05)$, as predicted. Higher team performance also was associated with a more equal participation rate among group members, measured as low dominance polarization, $r(22)=-.49, p<.05$.

Illustrative Team Diagrams. The team in Figure 7 had the highest performance scores in the study and is an example of a Unified Group. The Tending-to-Polarize Team in Figure
8 performed below average, had one of the most negative and task-oriented centers of gravity in the study, and had one of the most negative base players. Results from other instruments also indicated that the team in Figure 8 had problems. Of all the teams, it was lowest on the cohesion measure of the Group Environment Scale (GES) and highest on the GES anger and aggression measure. As can be seen, TDM highlights specific behaviors that contribute to these findings and increases our understanding of how to alleviate problems through training and interventions.

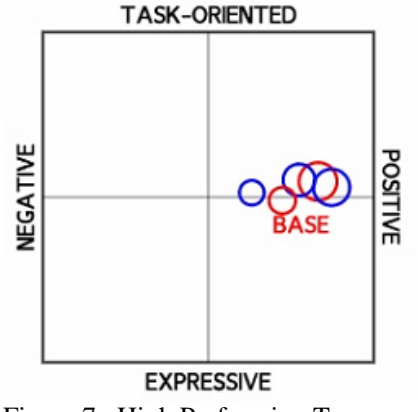

Figure 7. High Performing Team

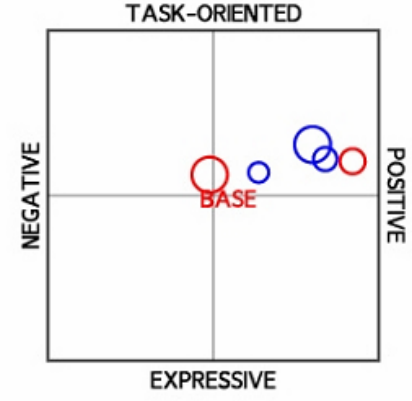

Figure 8. Low Performing Team

\section{DISCUSSION}

Stability. In general, TDM variables were satisfactorily stable over time, especially those on the dominance and dominance polarization dimension.

Changes over time. The centers of gravity in the groups became more positive and more expressive between the two rating times and the average dominance rating increased, suggesting an improvement in team functioning over time.

Overall associations. Despite the fact that the teams were very similar to each other with low average distances and positive centers of gravity, all but one of the TDM variablesthe index of polarization-were associated with other measures used in this study. (The index of polarization would not be expected to be related to important dynamics in a team with a tight clustering of behaviors.)

Social and task cohesion ratings. The TDM variables were associated as predicted with the social and task cohesion ratings with the exception of dominance polarization. It is noteworthy also that there were negative correlations between the task and social cohesion ratings and many of the standard deviations of the TDM measures such as average distance, positive center of gravity, and dominance levels. This is in line with the underlying premise of TDM, which is that the more dispersed the scores, the less cohesion and the more conflict, and is supported by Bell's findings (2007) in a metaanalysis that greater dispersal of team scores on Agreeableness (from the Five Factor Model-see Costa \& McCrae, 1992) was related to lower team performance.

Group Environment Scale. Two of the TDM variables were associated with the cohesion scale on the Group Environment Scale: higher average dominance and a more expressive center of gravity. Other TDM variables were 
associated with other GES scales, e.g., a high GES anger and aggression score was associated with high average distance and a more negative center of gravity.

Performance. Two TDM variables were associated with higher team performance: lower polarization on the dominance dimension (i.e. more equal participation), and a more expressive center of gravity.

Expressive behavior. Regarding the importance of behavior on the expressive dimension in adult working groups, it should be noted that the simulation task was highly structured. Bales (1953) described how members of a healthy group or team oscillate between positive task-oriented behaviors and positive expressive behaviors. The expressive behaviors are frequently joking, playful behaviors, which give team members a break from task demands. Without this cycle of positive expressive behaviors, the team is likely to be too task oriented and may experience task stress as negative (Clarke \& Ritscher, 2004) or find the team dry and boring. Team members who engage in expressive behavior are therefore valuable in highly-structured work teams such as these. Conversely, in less highly-structured groups, such as classroom groups, too much expressive behavior can interfere with task performance (see MacCoun, 1993, for a review of this literature).

Conclusion. The TDM variables were shown to be associated with other measures of cohesion and with performance. The Team Diagramming Method was also shown to illuminate the contribution of individual behaviors to cohesion and team functioning and therefore to be helpful in diagnosing problems as well as in designing and testing interventions. An example of an intervention that can be tested is the effect of adding a team member who is good at engaging in joking, expressive behavior. The quantitative nature of the approach enables comparison of teams with different behaviors at different times and should help answer longdebated research questions.

\section{ACKNOWLEDGEMENTS}

This research was supported by the National Space Biomedical Research Institute through NCC 9-58 and the NASA Behavioral Health and Performance Element of the Human Research Program.

\section{REFERENCES}

Bales, R. F. (1953). Equilibrium problem in small groups. In T. Parsons, R. F. Bales \& E. A. Shils (Eds.), Working Papers in the Theory of Action (pp. 111-161): Free Press.

Bales, R. F., \& Cohen, S. P. (1979). SYMLOG: A system for the multiple level observation of groups. NY: The Free Press.

Bell, S. T. (2007). Deep-level composition variables as predictors of team performance: A meta-analysis. J. Applied Psychology, 92(3), 595-615.

Carron, A. V., Colman, M. M., Wheeler, J., \& Stevens, D. (2002). Cohesion and performance in sport: A meta-analysis. Journal of Sport and Exercise Psychology, 24, 168-188.

Clarke, L., \& Ritscher, J. B. (2004). Humor as a potential training factor for International Space Station program personnel. Aviaion, Space, \& Environmental Medicine, 75, B61.

Costa, P. T., Jr., \& McCrae, R. R. (1992). NEO PI-R Professional Manual. Odessa, FL: Psychological Assessment Resources, Inc.
Couch, A. (1960). Psychological determinants of interpersonal behavior. Harvard University. Unpublished doctoral dissertation.

Eid, J., \& Johnsen, B. H. (2002). Acute stress reactions after submarine accidents. Military Medicine, 167(5), 427-431.

Emmerich, W. (1968). Personality development and concepts of structure. Child Development, 39, 671-690.

Emmerich, W. (1973). Structure and development of personal-social behaviors in economically disadvantaged preschool children. Princeton: Educational Testing Service.

Entin, E. E., Kerrigan, C., Serfaty, D., \& Yound, P. (1998). Development of a search and rescue simulation to study the effects of prolonged isolation on decision making (TR-853). Burlington, MA: Alphatech, Inc.

Fine, G. A. (1986). Behavioral change in group space: A reintegration of Lewinian theory in small group research. Advances in Group Processes, 3, 23-50.

Fischer, U., McDonnell, L., \& Orasanu, J. (2007). Linguistic correlates of team performance: Toward a tool for monitoring team functioning during space missions. Aviation, Space and Environmental Medicine: Operational Applications of Cognitive Performance Enhancement Technologies, 78(5), II, B86-95.

Isenberg, D. J., \& Ennis, J. G. (1981). A comparison of derived and imposed dimensions. J. of Personality and Social Psychology, 41(2), 293-305.

Jaffe, E. D., \& Nebebzahl, I. D. (1990). Group interaction and business game performance. Simulation \& Gaming, 21(2), 133-146.

Keyton, J., \& Springston, J. (1990). Redefining cohesiveness in groups. Small Group Research, 21(2), 234-254.

MacCoun, R. J. (1993). Unit cohesion and military performance. In Sexual orientation and U.S. military personnel policy: Policy options and assessment. Santa Monica: National Defense Research Institute, RAND, (pp. 283-331).

Moos, R. H., \& Humphrey, B. (1974). Group Environment Scale, Form R. Palo Alto: Consulting Psychologists Press.

Moreno, J. L. (1960). The Sociometry Reader. NY: The Free Press.

Mullen, B., \& Copper, C. (1994). The relation between group cohesiveness and performance: An integration. Psych.l Bulletin, 115(2), 210-227.

Oliver, L. W., Harman, J., Hoover, E., Hayes, S. M., \& Pandhi, N. A. (2000). A quantitative integration of the military cohesion literature. Military Psychology, 11(1), 57-83.

Orasanu, J., Fischer, U., Parke, B., McDonnell, L., Kraft, N., \& Anderson, B. (2009). Alternative Techniques for Monitoring and Evaluating Team Cohesion. Final Report submitted to the Behavioral Health and Performance Element, NASA Human Research Program. Moffett Field, CA: NASA.

Parke, B. (1985). A field adaptation of the SYMLOG adjective rating form suitable for populations including children. International Journal of Small Group Research, 1(1), 89-95.

Parke, B., \& Houben, H. C. (1985). An objective analysis of group types. International Journal of Small Group Research, 13, 131-149.

Parke, B., \& Houben, H. C. (1988). Analyses of subgroups and clusterings within groups: Attaining knowledge of the social interaction potential. International Journal of Small Group Research, 4, 143-158.

Parke, B., Kanki, B., Nord, K., \& Bianchi, A. (2000). Crew climate and performance: Use of group diagrams based on behavioral ratings, Proceedings of the 44th International Ergonomics Association/HFES Congress, 3149-3152. San Diego, CA.

Phipps, S., \& Mulhern, R. K. (1995). Family cohesion and expressiveness promote resilience to the stress of pediatric bone marrow transplant: A preliminary report. Developmental and Behavioral Pediatrics, 16(4), 257263.

Rywick, T. (1987). SYMLOG rating form reliability. International Journal of Small Group Research, 3(1), 119-125.

Schaefer, E. S. (1971). Development of hierarchical configurational models for parent behavior and child behavior. In J. P. Hill (Ed.), Minnesoto Symposia on Child Psychology (Vol. 5). Minneapolis: University of Minnesota Press.

Schaefer, E. S., Droppleman, L. F., \& Kalverboaer, A. F. (1965). Development of a classroom behavior checklist and factor analyses of children's school behavior in the United States and the Netherlands. Bethesda, Maryland: National Institute of Mental Health.

Wish, M., D'Andrade, R. G., \& Goodnow, J. E. (1980). Dimensions of interpersonal communication: Correspondences between structures for speech acts and bipolar scales. J. Personality and Social Psychology, 39(5), 848-860. 